\title{
Analysis of a Novel Soft Switching Bidirectional DC-DC Converter
}

\author{
Ju-Kyoung Eom ${ }^{*}$, Jun-Gu Kim ${ }^{*}$, Jae-Hyung Kim ${ }^{* *}$, Soon-Tack $\mathrm{Oh}^{* * *}$, Yong-Chae Jung ${ }^{* * * *}$, \\ and Chung-Yuen Won ${ }^{\dagger}$ \\ ${ }^{\dagger *}$ College of Information and Communication Engineering, Sungkyunkwan University, Suwon, Korea \\ ${ }^{* *}$ Samsung Techwin Co. Ltd., Seongnam, Korea \\ ${ }^{* * *}$ Samsung Electro-Mechanics Co. Ltd., Suwon, Korea \\ ${ }^{* * * *}$ Department of Electronic Engineering, Namseoul University, Cheonan, Korea
}

\begin{abstract}
In this paper, a novel bidirectional DC-DC converter employing soft switching technique was proposed. Compare to conventional bidirectional converters, the main switches of proposed converter are operated without switching losses. Moreover, auxiliary switches are used, and the switches are operated under zero voltage switching (ZVS) and zero current switching (ZCS) condition. To verify the validity of the proposed converter, mode analysis, design procedure, simulation and experimental results are presented.
\end{abstract}

Key words: Bidirectional converter, DC-DC Converter, Soft-switching, ZCS, ZVS

\section{INTRODUCTION}

With the limited fossil fuel problem, renewable energy became the center of public interest. Therefore, power electronics applying to alternative energy application field such as photovoltaic generation, fuel cell and electric vehicles became a matter of common interest as well [1]-[3]. In these applications, an energy storage system like a battery system must be needed to save and use energy. Thus, a bidirectional DC-DC converter which allows transfer power between two DC sources become an important topic of power electronics. The bidirectional DC-DC converter is categorized into an isolated converter [4]-[6] and a non-isolated converter [7], [8]. The demands of bidirectional DC-DC converter are smaller size, lighter weight and higher efficiency etc.. In order to minimize the size of conventional bidirectional DC-DC converter, the switching frequency must be increased. However, the increase of switching frequency results in higher switching

Manuscript received Oct. 4, 2011; revised Oct. 16, 2012.

Recommended for publication by Associate Editor Honnyong Cha.

† Corresponding Author: woncy@skku.edu

Tel: +81-31-290-7115, Fax: +81-31-299-4623, Sungkyunkwan Univ.

*College of Information and Communication Eng., Sungkyunkwan Univ., Korea

**Samsung Techwin Co. Ltd., Korea

***Samsung Electro-Mechanics Co. Ltd., Korea

****Department of Electronic Eng., Namseoul University, Korea losses.

Since the switch mode power conversion system is employed for every alternative energy generation system and the efficiency of the power conversion system is in close connection with that of entire system, the researches of inverter and converter have processed vigorously. Particularly, in order to reduce switching losses that occur from the switch operation, soft switching methods using ZVS (zero voltage switching) and ZCS (zero current switching) have been studied [9]-[16].

In the case of conventional bidirectional DC-DC converter, the main switches operate under hard switching [11], [15-16] condition in boost mode and buck mode. Since this switching loss is one of serious dissipation, it is able to be caused to drop the efficiency of system. General method to prevent efficiency droop is that auxiliary switches without auxiliary circuit are employed to help the ZVS and ZCS operation [16]-[19] of the main switches. Although bidirectional DC-DC converter using only two auxiliary switches shows better performance than conventional bidirectional DC-DC converter, the two auxiliary switches operate under hard switching condition, and check the materialization of high efficient converter.

In order to deal with the hard switching problem, not only auxiliary switches but also auxiliary resonant circuit is employed. That is, two auxiliary switches, resonant 


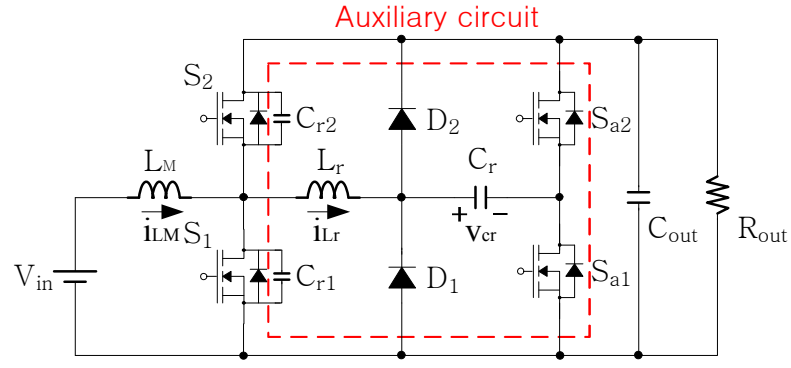

Fig. 1. Proposed bidirectional DC-DC converter.

capacitors and resonant inductor help the main and auxiliary switches to turn on and off under ZVS and ZCS condition.

In this paper, the operational characteristics are presented and the analysis of each operational mode is explained through using mathematical equations. In order to verify the validity of the paper, simulation and experimental results are given.

\section{PROPOSED BIDIRECTIONAL CONVERTER}

The proposed bidirectional DC-DC converter is shown in Fig. 1. In order to reduce the switching loss, a few passive elements are added and the elements are shown in the dotted line. That is, the proposed converter consists of main switches $\left(S_{1}, S_{2}\right)$, auxiliary switches $\left(S_{a 1}, S_{a 2}\right)$, two auxiliary resonant capacitors $\left(C_{r l}, C_{r 2}\right)$, two freewheeling diodes $\left(D_{l}\right.$, $\left.D_{2}\right)$, a resonant inductor $\left(L_{r}\right)$, and a main resonant capacitor
$\left(C_{r}\right) . L_{r}$ and $C_{r}$ operate as a resonant tank in order to help the soft switching operation of main and auxiliary switches.

Following assumptions are built to simplify the steady state analysis of the proposed topology during one switching cycle.

1) All switching devices and passive elements are ideal

2) The input voltage $\left(V_{\text {in }}\right)$ and output voltage $\left(V_{\text {out }}\right)$ are constant.

3) All equations are derived, assuming that the starting point of each mode is zero.

During one period of time, the operation of the proposed converter in boost mode can be divided into nine modes as shown in Fig. 2, and the key waveforms of each component are shown in Fig. 3.

Mode 1( $\left.t_{0} \leq t<t_{1}\right)$ : At $\mathrm{t}=\mathrm{t}_{0}$, the auxiliary switch $\left(S_{a l}\right)$ is turned on under ZCS condition. While the current flows through the main inductor and anti-parallel diode of upper main switch $\left(S_{2}\right)$, resonant current flows through the resonant tank $\left(L_{r}\right.$ and $\left.C_{r}\right)$. Meanwhile, the current flowing through the main inductor is decreased linearly, the resonant inductor and resonant capacitor resonate, and at the end of this mode, the same amount of current flows through not only main inductor but also resonant components. Key equations that describe the operation of this mode are provided.

$$
i_{L M}(t)=i_{L M}\left(t_{0}\right)-\frac{1}{L_{M 1}}\left(V_{O}-V_{i n}\right) t
$$
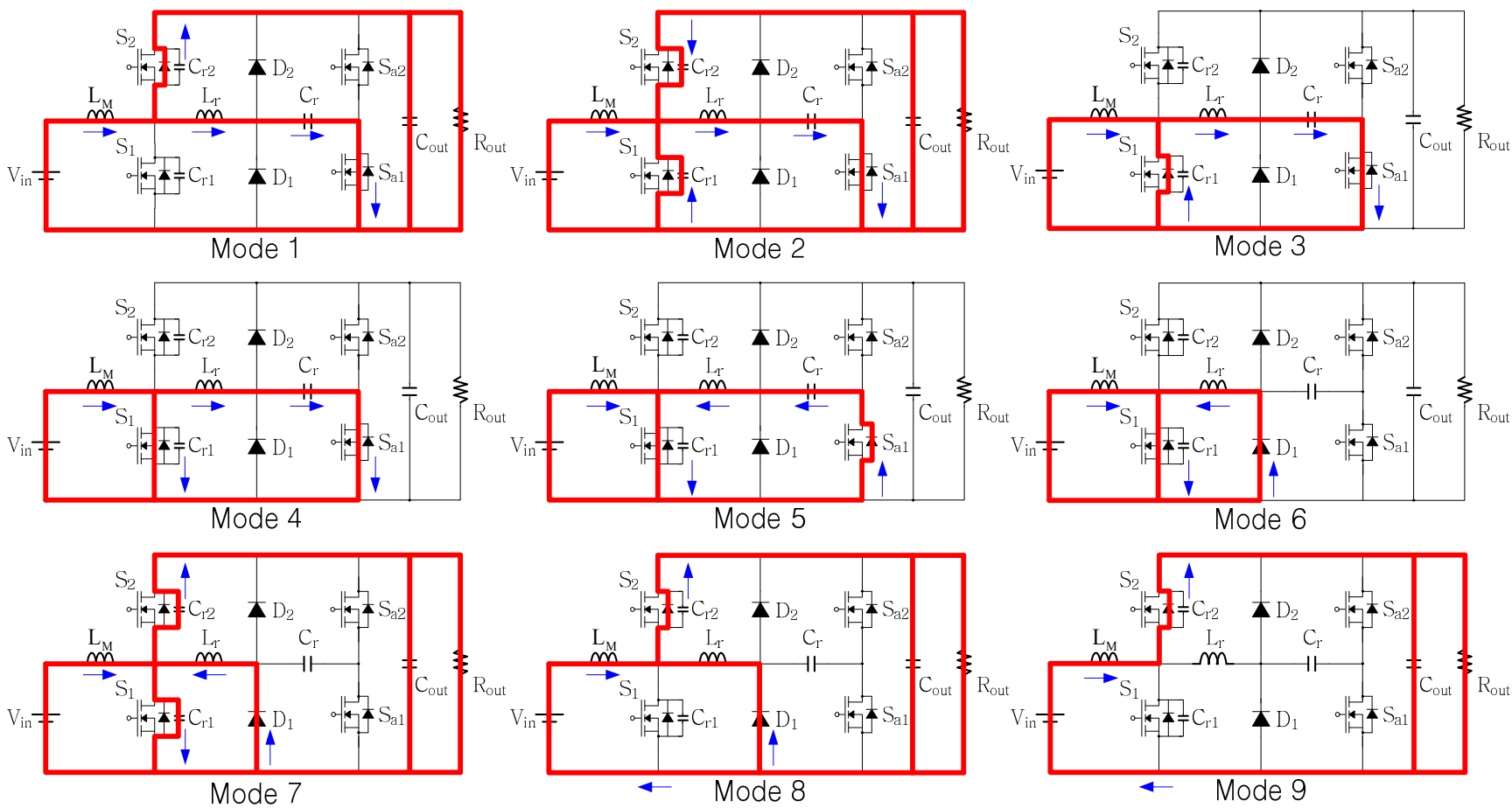

Fig. 2. Operational modes of the proposed converter in boost mode. 


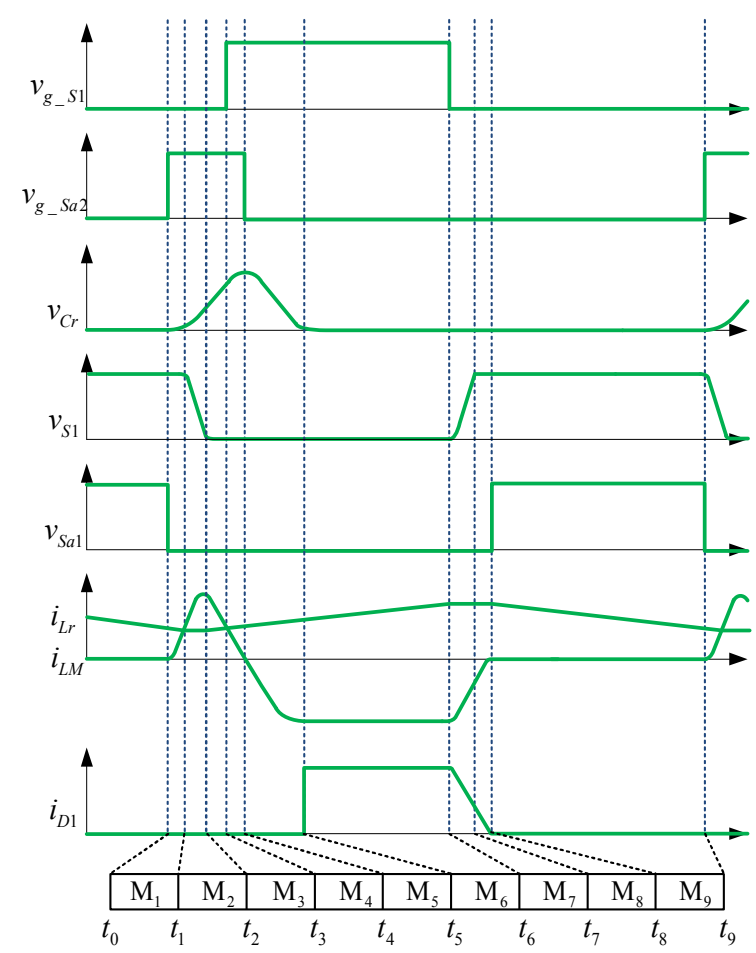

Fig. 3. Key waveforms of the proposed converter.

$$
\begin{gathered}
i_{L r}(t)=\frac{V_{C r}\left(t_{0}\right)-V_{O}}{Z_{r}} \sin \omega_{r} t \\
v_{C r}(t)=\left(V_{o}-V_{C r}\left(t_{0}\right)\right) \cdot \cos \omega_{r} t \\
i_{L r}\left(t_{0}\right)=0, \quad v_{C r}(t)=0, \quad i_{L M}\left(t_{1}\right)=I_{M 1}
\end{gathered}
$$

where the resonant angular frequency and resonant impedance can be defined by the following equations.

$$
\omega_{r}=\frac{1}{\sqrt{L_{r} C_{r}}}, Z_{r}=\sqrt{\frac{L_{r}}{C_{r}}}
$$

Mode 2( $\left.t_{1} \leq t<t_{2}\right)$ : During this mode, the resonance occurs between the two auxiliary resonant capacitors, $C_{r l}$ and $C_{r 2}$, and the resonant tank. At the same time, $C_{r l}$ is discharged and $C_{r 2}$ is charged. Key equations that describe the operation of this mode are provided.

$$
\begin{gathered}
i_{L M}(t) \approx I_{M 1} \\
i_{L r}(t)=\frac{C_{s}}{C_{a}} I_{M 1}+\left(1-\frac{C_{s}}{C_{a}}\right) I_{M 1} \cos \omega_{s} t+\frac{V_{o}-V_{i n}}{Z_{s}} \sin \omega_{s} t \\
v_{C r}(t)=\frac{I_{M 1}}{C_{a}}+Z_{s} I_{M 1}\left(1-\frac{C_{s}}{C_{a}}\right) \sin \omega_{s} t-\left(V_{O}-V_{i n}\right) \cos \omega_{s} t \\
v_{C r 1}(t)=\left(\frac{V_{1}}{C_{a}}+\frac{V_{O}}{C_{r}}\right) C_{S}+\left(\frac{C_{S} I_{M 1}}{C_{a} C_{r}}\right) t \\
-\left\{\left(\frac{V_{1}}{C_{a}}+\frac{V_{O}}{C_{r}}\right) C_{S}-V_{O}\right\} \cos \omega_{s} t-\left(\frac{C_{S} I_{M 1}}{C_{a} C_{r}} \sqrt{L_{r} C_{S}}\right) \sin \omega_{s} t
\end{gathered}
$$

$$
v_{C r 2}(t)=V_{O}-v_{C a 1}(t)
$$

Note that in order to simplify the high order functions of this mode, an assumption was built. The assumption is that since the variation of current flowing through main inductor is too small to consider, the main inductor current is regarded as a current source, and $C_{s}$ and $C_{a}$ are defined as the following equations.

$$
\begin{gathered}
C_{S}=\frac{C_{a} C_{r}}{C_{a}+C_{r}}, \quad C_{a}=C_{r 1}+C_{r 2} \\
\omega_{s}=\frac{1}{\sqrt{L_{r} C_{s}}}, \quad \omega_{a}=\frac{1}{\sqrt{L_{r} C_{a}}}, \quad Z_{s}=\sqrt{\frac{L_{r}}{C_{s}}}, \quad Z_{a}=\sqrt{\frac{L_{r}}{C_{a}}}
\end{gathered}
$$

Mode 3( $\left.t_{2} \leq t<t_{3}\right)$ : When the charging and discharging of two auxiliary resonant capacitors are finished at $t=t_{2}$, this mode begins. The resonant tank $\left(L_{r}\right.$ and $\left.C_{r}\right)$ resonates continuously through auxiliary switch and anti-parallel diode of main switch. Since the main switch is turned on while the current flows through anti-parallel diode of $S_{l}$, the switch can be turned on under ZVS condition.

$$
\begin{gathered}
i_{L M}(t)=\frac{1}{L_{M}} V_{i n} t+I_{M 1} \\
i_{L r}(t)=I_{r 2} \cos \omega_{r} t-\frac{V_{C r}\left(t_{2}\right)}{Z_{r}} \sin \omega_{r} t \\
v_{C r}(t)=I_{r 2} Z_{r} \sin \omega_{r} t+v_{C r}\left(t_{2}\right) \cdot \cos \omega_{r} t \\
i_{L M}\left(t_{3}\right)=I_{M 3}, \quad i_{L r}\left(t_{3}\right)=I_{r 3}
\end{gathered}
$$

Mode 4(t $\left.t_{3} \leq t<t_{4}\right)$ : When the main inductor current becomes larger than the resonant inductor current, this mode starts. During the previous mode, the main switch has already been turned on. Thus, the resonant current flows via main switch instead of anti-parallel diode. At $t_{4}$, the resonant inductor current is zero and the voltage of $C_{r}$ has peak value. At this moment, the auxiliary switch is turned off under ZCS condition. The main inductor current and resonant inductor current are expressed by equations (17) (20).

$$
\begin{gathered}
i_{L M}(t)=\frac{1}{L_{M}} V_{i n} t+I_{M 3} \\
i_{L r}(t)=I_{r 3} \cos \omega_{r} t-\frac{V_{C r}\left(t_{3}\right)}{Z_{r}} \sin \omega_{r} t \\
v_{C r}(t)=I_{r 3} Z_{r} \sin \omega_{r} t+v_{C r}\left(t_{3}\right) \cdot \cos \omega_{r} t \\
i_{L M}\left(t_{4}\right)=I_{M 4}, i_{L r}\left(t_{4}\right)=I_{r 4}
\end{gathered}
$$

Mode 5 $\left(t_{4} \leq t<t_{5}\right)$ : From $t=t_{4}$, the resonant inductor and 
resonant capacitor resonate reversely. Due to that reason, the direction of current is changed, and the anti-parallel diode of auxiliary switch is conducted. At the end of this mode, resonant tank stops the resonance, and any current is not flowing via the $C_{r}$ and the lower auxiliary switch.

$$
\begin{gathered}
i_{L M}(t)=\frac{1}{L_{M}} V_{i n} t+I_{M 4} \\
i_{L r}(t)=I_{r 4} \cos \omega_{r} t-\frac{V_{C r}\left(t_{4}\right)}{Z_{r}} \sin \omega_{r} t \\
v_{C r}(t)=I_{r 4} Z_{r} \sin \omega_{r} t+v_{C r}\left(t_{4}\right) \cdot \cos \omega_{r} t \\
i_{L M}\left(t_{5}\right)=I_{M 5}, i_{L r}\left(t_{5}\right)=I_{r 5}
\end{gathered}
$$

Mode $\mathbf{6}\left(\boldsymbol{t}_{5} \leq \boldsymbol{t}<\boldsymbol{t}_{6}\right)$ : Since the resonant capacitor is discharged completely, the resonant inductor current is running through different current path. That is, the current is flowing through freewheeling diode $\left(D_{l}\right)$. During this mode, the main inductor accumulates energy. However, the current flowing through the freewheeling diode and the resonant inductor maintains constant value. The main inductor current and resonant inductor current are expressed by equation (25) $\sim(27)$.

$$
\begin{gathered}
i_{L M}(t)=\frac{1}{L_{M}} V_{S} t+I_{M 5} \\
i_{L r}(t)=I_{r 5} \\
i_{L M}\left(t_{6}\right)=I_{M 6}, i_{L r}\left(t_{6}\right)=I_{r 5}
\end{gathered}
$$

Mode $7\left(t_{6} \leq t<t_{7}\right)$ : In this mode, all switches are turned off. Moreover, this mode is the second auxiliary resonant mode. Since the direction of current is changed, resonant capacitors, $C_{r l}$ and $C_{r 2}$, discharged and charged respectively in mode 2 are charged and discharged respectively. That is, as previously mentioned, the two resonant capacitors show complementary operation. At the end of this mode, main switch voltage becomes equal to output voltage, and when the capacitors finish their operation, this mode is finished.

$$
\begin{gathered}
i_{L M}(t)=I_{M 6} \\
i_{L r}(t)=I_{M 6}+\left(I_{r 5}-I_{M 6}\right) \cos \omega_{a} t \\
v_{C r 1}(t)=\left(I_{M 6}-I_{r 5}\right) Z_{a} \sin \omega_{a} t \\
v_{C r 2}(t)=V_{O}-\left(I_{M 6}-I_{r 5}\right) Z_{a} \sin \omega_{a} t
\end{gathered}
$$

Mode $8\left(t_{7} \leq t<t_{8}\right)$ : Since the state of main switch and auxiliary switch are the same as previous mode, the remaining current of resonant inductor flows through the anti-parallel diode of $S_{2}$. During mode 7, $C_{r 1}$ and $C_{r 2}$ finished the resonant operation. Thus any current does not flow through the anti-parallel diode of lower main switch in this mode. When the resonant inductor current becomes zero, mode 8 is finished.

$$
\begin{gathered}
i_{L M}(t)=I_{M 6}-\frac{1}{L_{M}}\left(V_{O}-V_{i n}\right) t \\
i_{L r}(t)=\frac{1}{L_{r}} V_{O} t+I_{r 6} \\
i_{L M}\left(t_{8}\right)=I_{M 8}, i_{L r}\left(t_{8}\right)=I_{r 8}
\end{gathered}
$$

Mode $9\left(t_{8} \leq t<t_{9}\right)$ : At $t=t_{8}$, the resonant inductor does not have any energy, and all switches are turned off. Therefore, the current flows through main inductor and the anti-parallel diode of $S_{2}$. At the end of this mode, the auxiliary switch is turned on, and the next switching cycle starts. The main inductor current is given by following equation.

$$
\begin{gathered}
i_{L M}(t)=I_{M 8}-\frac{1}{L_{M}}\left(V_{O}-V_{\text {in }}\right) t \\
i_{L r}(t)=0 \\
i_{L M}\left(t_{9}\right)=I_{M 0}, i_{L r}\left(t_{9}\right)=I_{r 0}
\end{gathered}
$$

In buck mode, the mode operation is divided into nine modes, and the analysis method is the same as that of boost mode. However, upper two switches, $S_{2}$ and $S_{a 2}$, are operated as a main switch and auxiliary switch respectively. Particularly, diode, $D_{2}$, is used as a buck mode freewheeling diode.

\section{ZVS CONDITION AND DESIGN PROCEDURES}

\section{A. ZVS Condition}

Fig. 4 shows the key waveforms of ZVS condition. In order to satisfy ZVS condition, the peak value of resonant inductor current has to be larger than that of main inductor [5]. However, depending on the peak value of resonant current, ZVS range is able to be changed, and the condition can be expressed with following equations,

$$
\begin{gathered}
I_{L r_{-} \text {peak }}>I_{L_{M_{-} \text {peak }}} \\
I_{L_{M-} \text { min }}+\frac{V_{o}}{Z_{r}}>I_{L_{M_{-} \text {min }}}+\Delta I_{L_{M}} \\
\frac{V_{o}}{Z_{r}}>\Delta I_{L_{M}} \\
I_{\text {Lr_peak }}=K I_{L_{M_{-} \text {peak }}}
\end{gathered}
$$

where $\mathrm{K}=$ constant coefficient between 1.2 and 1.5 


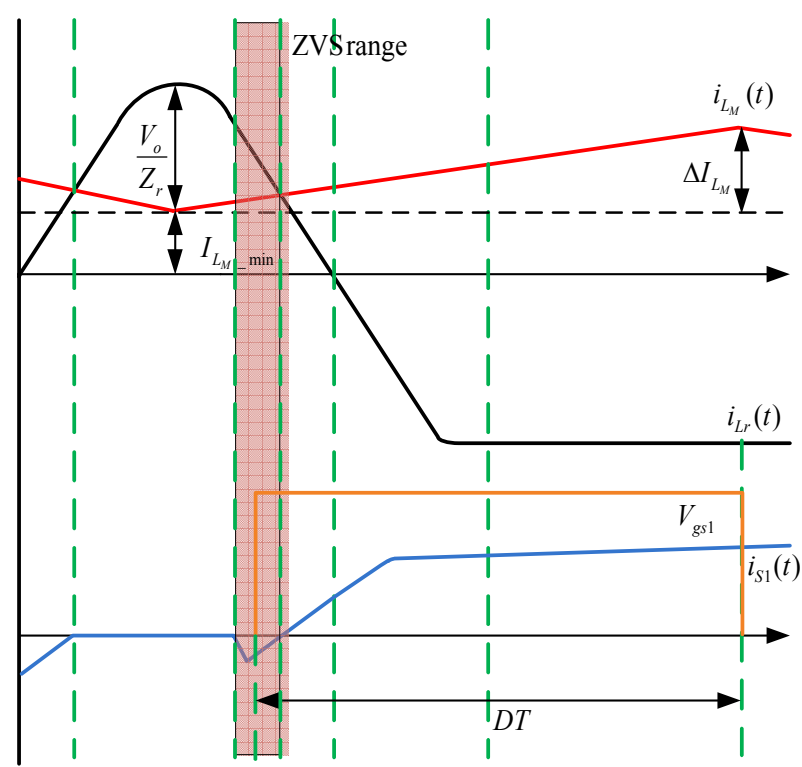

Fig. 4. Key waveforms of ZVS condition.

Consequently, the peak value of the resonant capacitor voltage, $V_{C r}$ can be equal to the output voltage or reduced by the values of resonant inductance and resonant capacitance. Therefore, the characteristic impedance formula of the series resonant tank is given by,

$$
Z_{o}=\frac{V_{C r_{-} \text {peak }}}{I_{L_{-} \text {peak }}}=\sqrt{\frac{L_{r}}{C_{r}}}
$$

Since the resonant period is related with the resonant frequency, $f_{r}=1 / T_{r}$, in order to acquire variable resonant period changed by $L_{r}$ and $C_{r}$, the above equation can be re-defined as following equation.

$$
T_{r}=2 \pi \sqrt{L_{r} C_{r}}=2 \pi \sqrt{\frac{L_{r}}{C_{r}}} C_{r}=2 \pi Z_{o} C_{r}
$$

With the derived equation, the available ranges of $L_{r}$ and $C_{r}$ can be defined, and the equations are given by,

$$
\begin{gathered}
C_{r}>\frac{T_{r}}{2 \pi Z_{o}} \\
L_{r}<Z_{o}^{2} C_{r}
\end{gathered}
$$

\section{B. Resonant Components and ZVS Range}

ZVS ranges within one switching cycle are shown in Fig. 5. Each curve indicates ZVS range base on coefficient, $K$, and resonant frequency. Since the coefficient and resonant frequency are related each other, depending on the coefficient, resonant frequency is able to be varied, and ZVS range can be changed as well. As shown in the Fig. 5, while the coefficient

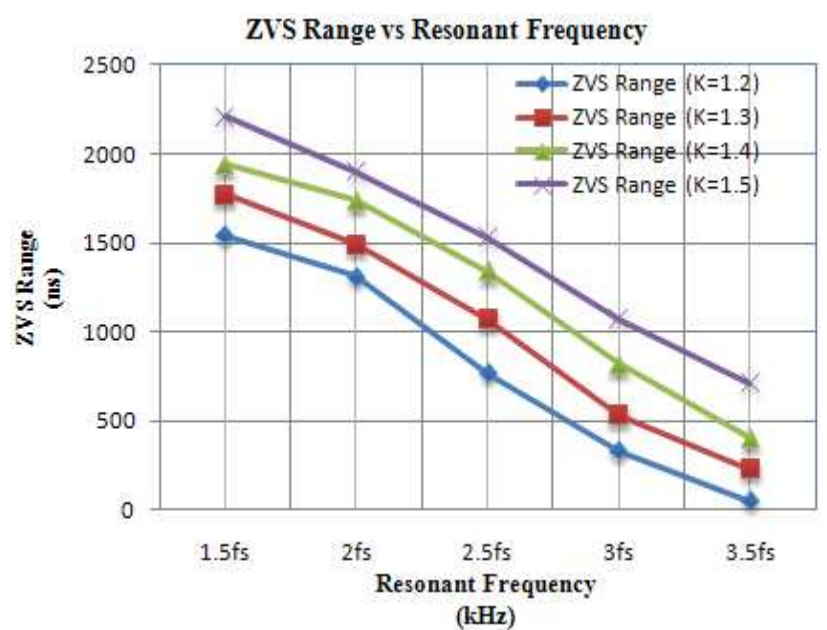

Fig. 5. ZVS range and resonant frequency.

is increased, ZVS range is also increased. On the other hand, according to the resonant frequency is increased, ZVS range is decreased. As the coefficient $K$ is increased, the resonant frequency can be decreased. However, the conduction loss is increased due to the increment of coefficient $K[20]$ since the ON time of gate signal is increased in order to qualify the current path for ZVS. Therefore, the most appropriate ZVS range has to be defined.

In this topology, 500[ns] is defined as a boundary for stable control of the main switch through employing the relation between ZVS range and resonant frequency of the series resonant tank. Moreover, when 500 [ns] is defined as a ZVS boundary, the corresponding coefficient is 1.3 , and corresponding resonant frequency is approximately $3.0 f_{s}$ as well.

\section{Auxiliary Resonant Capacitor $\left(C_{r 1}\right.$ and $\left.C_{r 2}\right)$}

In this topology, the auxiliary resonant capacitors, $C_{r l}$ and $C_{r 2}$, are connected in parallel with upper and lower main switches in order to secure current path for resonance occurring in mode 2 and mode 7. Since those capacitors are charged and discharged complementary by the difference between resonant inductor current and main inductor current, $C_{r 1}$ and $C_{r 2}$ must be sufficiently larger than output capacitor, $C_{\text {OSS }}$. Thus, it is assumed that the resonant capacitance value has to be 20 times bigger than the output capacitance of switch and the equation can be written as follows,

$$
C_{r 1} \text { and } C_{r 2}>20 C_{\text {oSS }}
$$

\section{Main Inductor Design}

Input power, output power, the ripple current of main inductor and efficiency have to be considered to design the main inductor. Typically, input power is designed with $10 \%$ or $20 \%$ margin since the efficiency of the converter is not able to be $100 \%$. From the above concept, the average and 
ripple current of the main inductor is calculated with following equations.

$$
\begin{aligned}
I_{L} & =\frac{P_{\text {in }}}{V_{\text {in_min }}} \\
\Delta I_{L} & =\frac{I_{L}}{1.7}
\end{aligned}
$$

From the above equations, the maximum and minimum currents are able to be derived, and the equations are given by,

$$
\begin{aligned}
& I_{L_{-} \max }=I_{L}+\frac{\Delta I_{L}}{2} \\
& I_{L_{-} \min }=I_{L}-\frac{\Delta I_{L}}{2}
\end{aligned}
$$

Moreover, the maximum and minimum duty ratio is depending on the input voltage.

$$
\begin{aligned}
D_{\text {max }} & =\frac{V_{o}-V_{\text {in_min }}}{V_{o}} \\
D_{\text {min }} & =\frac{V_{o}-V_{\text {in_max }}}{V_{o}}
\end{aligned}
$$

From the derived equations, switch turn on time, $T_{\text {on }}$, and the inductance value of main inductor are able to be defined like the following equations.

$$
\begin{gathered}
T_{o n}=D_{\text {max }} T=\frac{D_{\max }}{f_{s w}} \\
L=\frac{V_{\text {in_min }_{\text {min }}} T_{o n}}{\Delta I_{L}}
\end{gathered}
$$

\section{E. Design Example}

Based on the derived equations, the design example of the proposed bidirectional DC-DC converter is able to be shown. Table I shows the design parameters of the proposed

TABLE I

DESIGN PARAMETERS

\begin{tabular}{c|c|c}
\hline PARAMETER & VALUE & UNIT \\
\hline \hline INPUT VOLTAGE & $200 \sim 350$ & $\mathrm{~V}_{\mathrm{dc}}$ \\
\hline OUTPUT VOLTAGE & 400 & $\mathrm{~V}_{\mathrm{dc}}$ \\
\hline INPUT POWER & 1.1 & $\mathrm{~kW}$ \\
\hline OUTPUT POWER & 1.0 & $\mathrm{~kW}$ \\
\hline EFFICIENCY & 91 & $\%$ \\
\hline OUTPUT CAPACITANCE & 320 & $\mathrm{pF}$ \\
\hline SWITCHING PREQUENCY & 30 & $\mathrm{kHz}$ \\
\hline
\end{tabular}

converter in boost mode. From the derived equations, main inductor average current, ripple current, maximum current and minimum current can be found.

$$
\begin{gathered}
I_{L}=\frac{P_{i n}}{V_{i n_{-} \min }}=\frac{1,100}{200}=5.5[\mathrm{~A}] \\
\Delta I_{L}=\frac{I_{L}}{1.7}=\frac{5.5}{1.7}=3.23[\mathrm{~A}]
\end{gathered}
$$

From the above equations, maximum and minimum main inductor currents are defined, and the values are as follows:

$$
\begin{aligned}
& I_{L_{-} \max }=I_{L}+\frac{\Delta I_{L}}{2}=5.5+\frac{3.23}{2}=7.12[\mathrm{~A}] \\
& I_{L_{-} \min }=I_{L}-\frac{\Delta I_{L}}{2}=5.5-\frac{3.23}{2}=3.88[\mathrm{~A}]
\end{aligned}
$$

The maximum duty ratio has to be defined primarily to find the switch on time. The values of maximum duty ratio and switch turn on time can be calculated as:

$$
\begin{gathered}
D_{\max }=\frac{V_{o}-V_{\text {in_min }}}{V_{o}}=\frac{400-200}{400}=0.5 \\
D_{\min }=\frac{V_{o}-V_{\text {in_max }}}{V_{o}}=\frac{400-350}{400}=0.125 \\
T_{o n}=D_{\max } T=\frac{D_{\max }}{f_{s w}}=\frac{0.5}{30 \times 10^{3}}=16.667[\text { usec] }
\end{gathered}
$$

Therefore, the main inductance can be written as (62):

$$
L=\frac{V_{\text {in_min }} T_{\text {on }}}{\Delta I_{L}}=\frac{200 \times 16.667 \times 10^{-6}}{3.23}=1.032[\mathrm{mH}]
$$

Moreover, the resonant inductance, $L_{r}$, and resonant capacitance, $C_{r}$, can be derived. That is, the peak resonant inductor current can be obtained by following equation:

$$
I_{L r_{-} \text {peak }}=K I_{L_{M_{-} \text {peak }}}=1.3 \times 7.12=9.256[\mathrm{~A}]
$$

From the above value, the resonant impedance can be expressed.

$$
Z_{o}=\frac{V_{C r_{-} \text {peak }}}{I_{L r_{-} \text {peak }}}=\frac{V_{o}}{I_{L r_{-} \text {peak }}}=\frac{400}{9.256}=43.2[\Omega]
$$

Based on the Fig. 5, the resonant frequency is determined as $3.0 f_{s}$,

$$
f_{r}=3.0 f_{S} \approx 90
$$


TABLE II

SIMULATION \& EXPERIMENTAL PARAMETERS.

\begin{tabular}{c|c|c}
\hline PARAMETER & VALUE & UNIT \\
\hline \hline INPUT VOLTAGE & 200 & $\mathrm{~V}_{\mathrm{dc}}$ \\
\hline OUTPUT VOLTAGE & 400 & $\mathrm{~V}_{\mathrm{dc}}$ \\
\hline MAIN INDUCTANCE & 1 & $\mathrm{mH}$ \\
\hline RESONANT INDUCTANCE & 50 & $\mu \mathrm{H}$ \\
\hline RESONANT CAPACITANCE & 50 & $\mathrm{nF}$ \\
\hline OUTPUT CAPACITANCE & 1000 & $\mu \mathrm{F}$ \\
\hline SWITCHING PREQUENCY & 30 & $\mathrm{kHz}$ \\
\hline
\end{tabular}

With derived values, the values of resonant inductance and resonant capacitance are able to be calculated by:

$$
\begin{gathered}
L_{r}<Z_{o}^{2} C_{r}=43.2^{2} \times 41 \times 10^{-9}=76.5[\mathrm{uF}] \\
C_{r}>\frac{T_{r}}{2 \pi Z_{o}}=\frac{11.11 \times 10^{-6}}{2 \pi \times 43.2}=41[\mathrm{nF}]
\end{gathered}
$$

From (46), the auxiliary resonant capacitors, $C_{r l}$ and $C_{r 2}$, can be calculated.

$$
C_{r 1} \text { and } C_{r 2}>20 C_{\text {OSS }}=20 \times 320 \times 10^{-12}=6.4[\mathrm{nF}]
$$

Therefore, in order to qualify the ZVS condition, $L_{r}=$ $50[\mu \mathrm{H}], C_{r 1}$ and $C_{r 2}=10[\mathrm{nF}]$, and $C_{r}=50[\mathrm{nF}]$ are selected as the resonant component values respectively.

\section{Simulation Results}

The simulation and experimental parameters are shown in TABLE II. In this paper, the proposed topology has been simulated by POWERSIM Inc. PSIM 6.0 software. The simulation has been performed under $30[\mathrm{kHz}]$ switching frequency and input voltage is fixed at 200[V]. Moreover the duty ratio of the simulation is 0.5 . In order to achieve the soft switching condition, sufficient switching time has to be secured. Namely, the auxiliary switch must be on state while the resonant capacitors, $C_{r 1}$ and $C_{r 2}$, are charged and discharged complementary. The auxiliary switch is turned off when the resonant capacitor voltage is at the vicinity of its peak. Thus, in order to qualify the above conditions, the main switch PWM signal is overlapped with the auxiliary switch PWM signal. The PWM signals are shown in Fig. 6.

In the Fig. 6, turn-on time of main switch $\left(D_{\text {main }} T\right)$ is controlled by conventional voltage and current control methods. But auxiliary switch helps the soft-switching of main switch. From mode 1 to mode 4 in the Fig. 3 is the part of occurring resonance with $L_{r}, C_{r}, C_{r 1}$ and $C_{r 2}$. When current

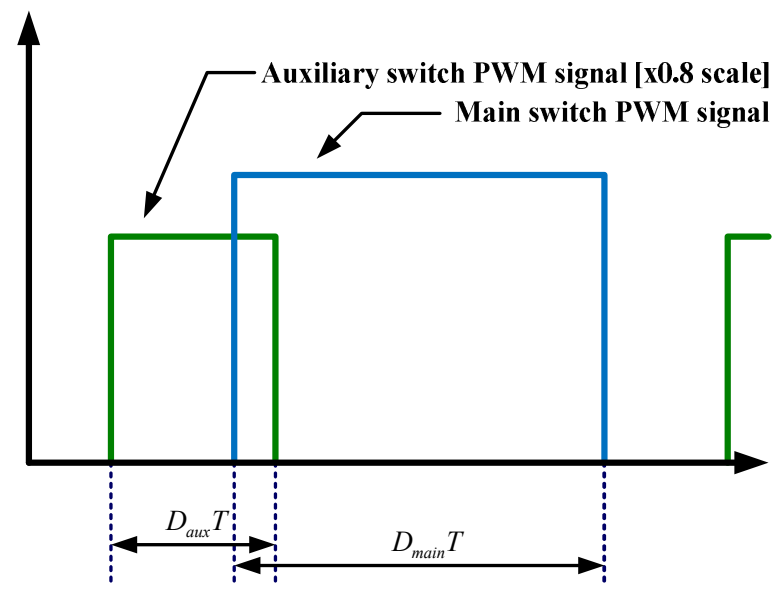

Fig. 6. PWM signals of the main and auxiliary switches.

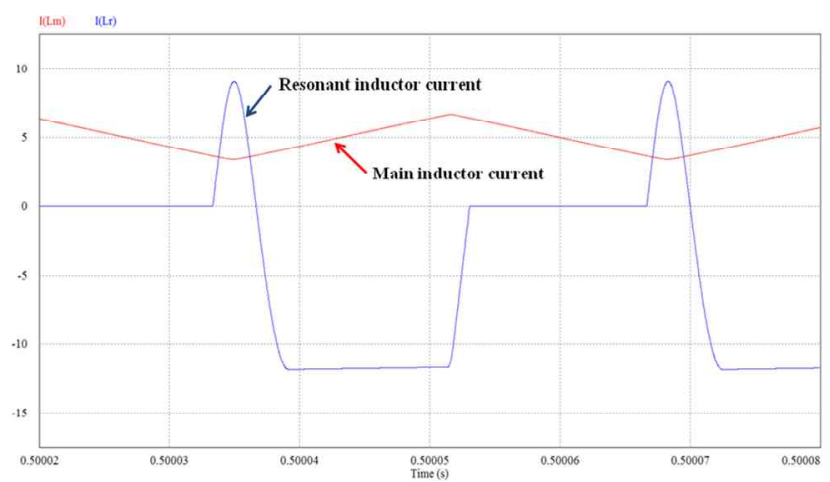

Fig. 7. Waveforms of main and resonant inductor current.

loop is made by auxiliary switch turn-on in the Fig. 3, the energy stored in the main switch output capacitor will be discharged and the voltage of the main switch will be decreased to the $0[\mathrm{~V}]$. After that, ZVS turn-on condition is built with activating main switch turned on. By using the former design data, auxiliary switch turn-on time $D_{a u x} T$ is derived by (69).

$$
D_{\text {aux }} T=\left[2 \pi \sqrt{\left(C_{r 1}+C_{r 2}+C_{r}\right) \times L_{r}}\right] \div 2=5.877 \text { [usec] }
$$

Fig. 7 shows the simulation waveforms of the main inductor and resonant inductor current. In order to achieve ZVS, several conditions should be qualified. One of the conditions is that resonant inductor current is larger than that of main inductor during certain period. As shown in the Fig. 7, resonant inductor current is larger than that of main inductor during mode 2 and mode 3 .

Fig. 8 and Fig. 9 show the simulation waveforms of the main switch and auxiliary switch voltage and current respectively. Before the main switch is turned on, body diode is conducted. As a result, the main switch is turned on under ZVS condition. Consequently, when the resonant tank has discharged and the current is flowing through the body diode, 


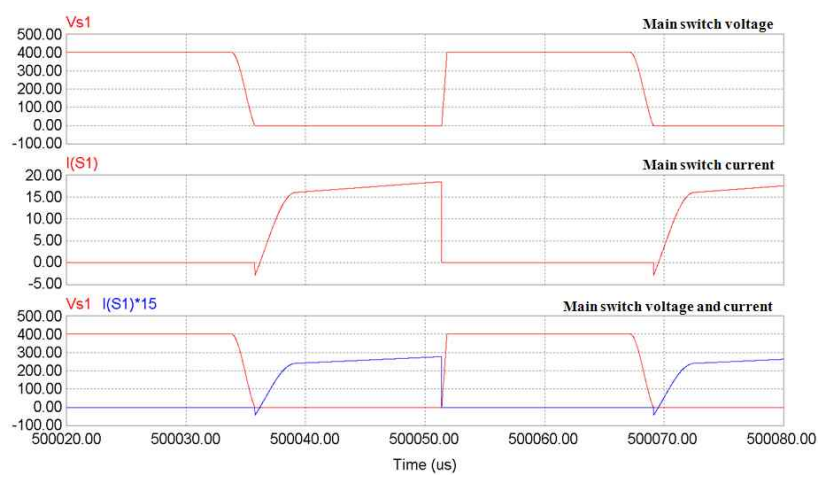

Fig. 8. Waveforms of main switch voltage and current

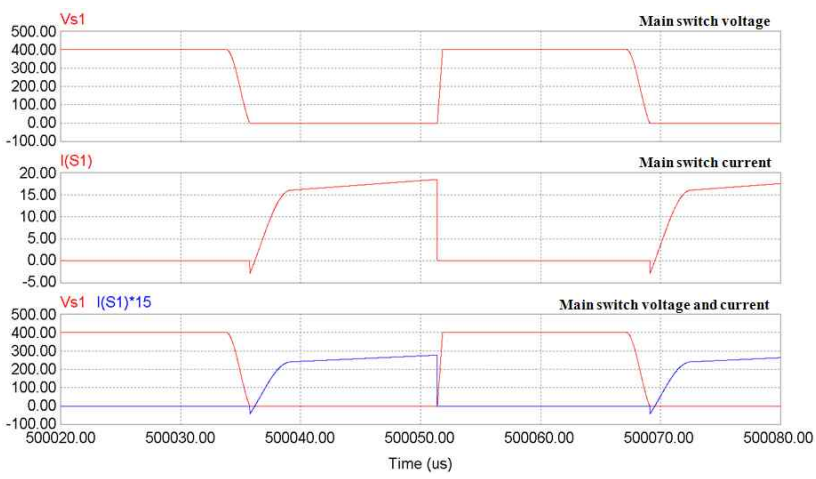

Fig. 9. Simulation waveforms of auxiliary switch voltage and current.

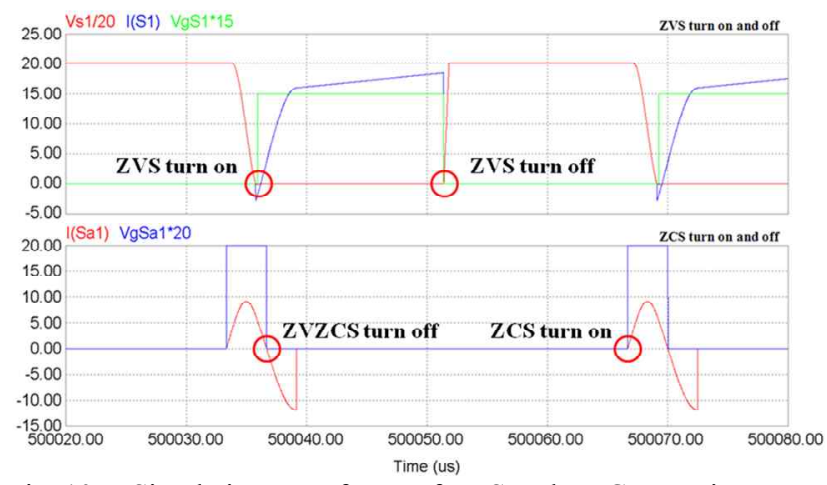

Fig. 10. Simulation waveforms of ZVS and ZVC operation.

the auxiliary switch is turned off. Therefore, the auxiliary switch is able to be operated under ZCS condition.

Fig. 10 shows the ZVS and ZCS operation of the main switch and auxiliary switch. Particularly, ZVS operation is achieved at the main switches, and ZCS operation is achieved at the auxiliary switches.

\section{EXPERIMENTAL RESULTS}

In order to verify the validity of the proposed bidirectional DC-DC converter, $1.0[\mathrm{~kW}]$ prototype was built. The experimental parameters are shown in TABLE II. The Fig. 11 shows the test bed of the proposed bidirectional converter.

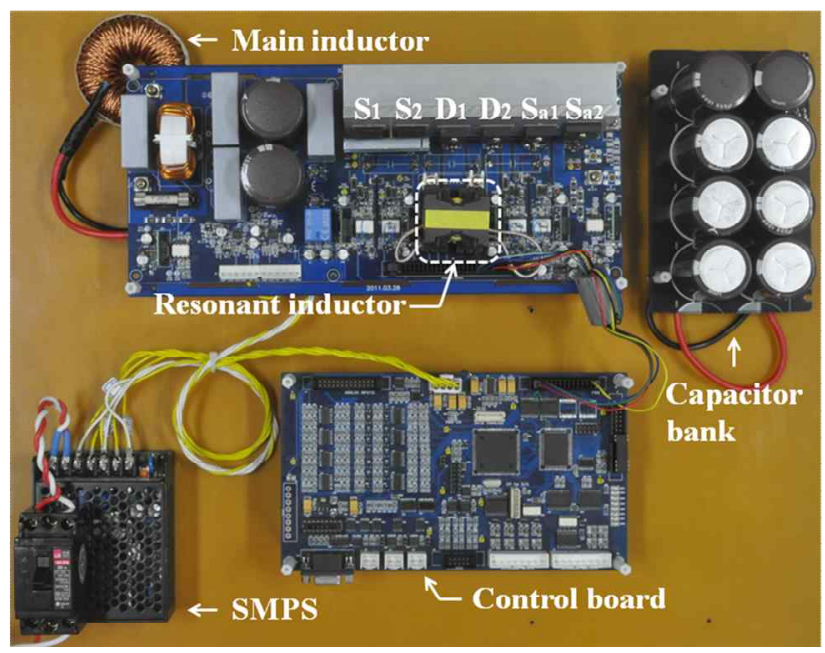

Fig. 11. The prototype of the proposed converter.

The proposed converter is regulated at $200\left[\mathrm{~V}_{\mathrm{dc}}\right] \sim 350\left[\mathrm{~V}_{\mathrm{dc}}\right]$ input voltage and $400\left[\mathrm{~V}_{\mathrm{dc}}\right]$ output voltage. Since the switching frequency of the converter is $30[\mathrm{kHz}]$, CoolMOS is employed as a switching devices.

The experimental waveforms are shown in Fig. 12 14. Fig. 12 shows the main inductor current and resonant inductor current. The experimental waveform shows almost the same results as simulation results shown in Fig. 7. However, compared with Fig. 7, the resonant inductor current is floating due to parasitic components.

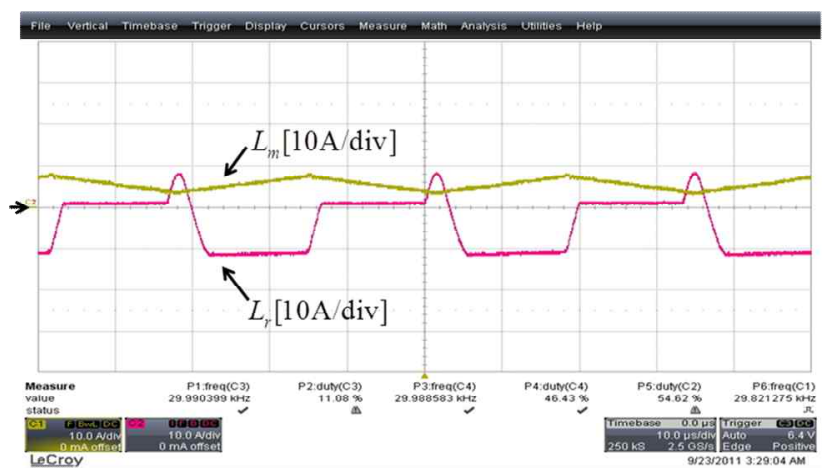

Fig. 12. The experimental waveforms of the main and resonant inductor currents.

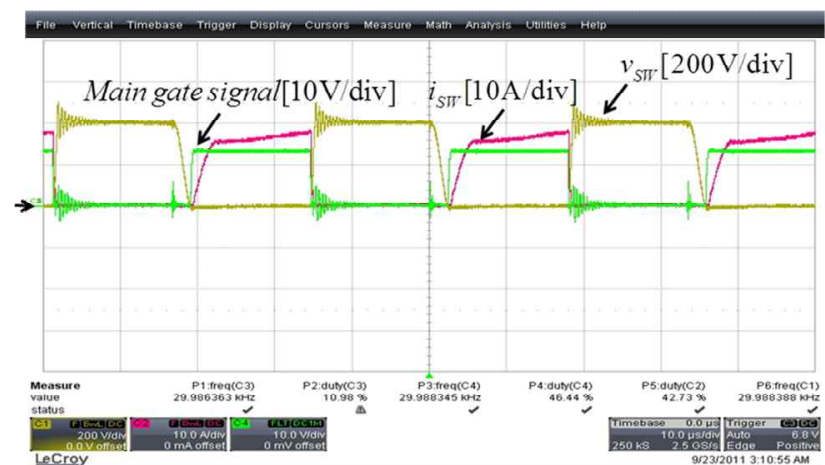

Fig. 13. The experimental waveforms of ZVS operation. 


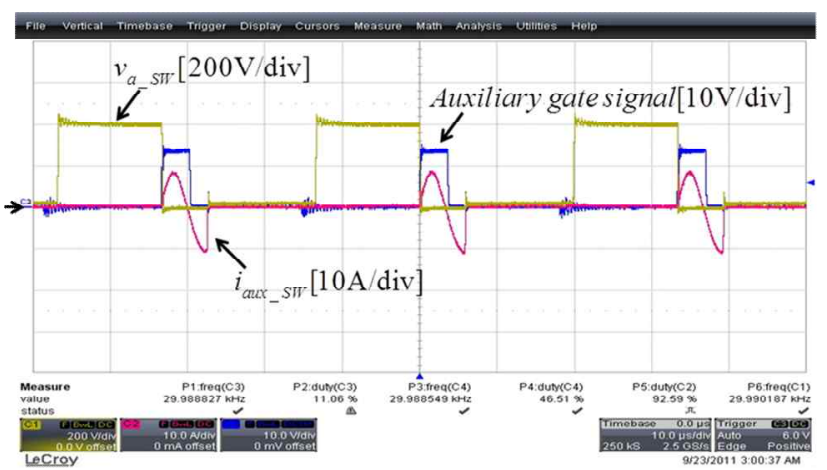

Fig. 14. The experimental waveforms of ZCS operation.

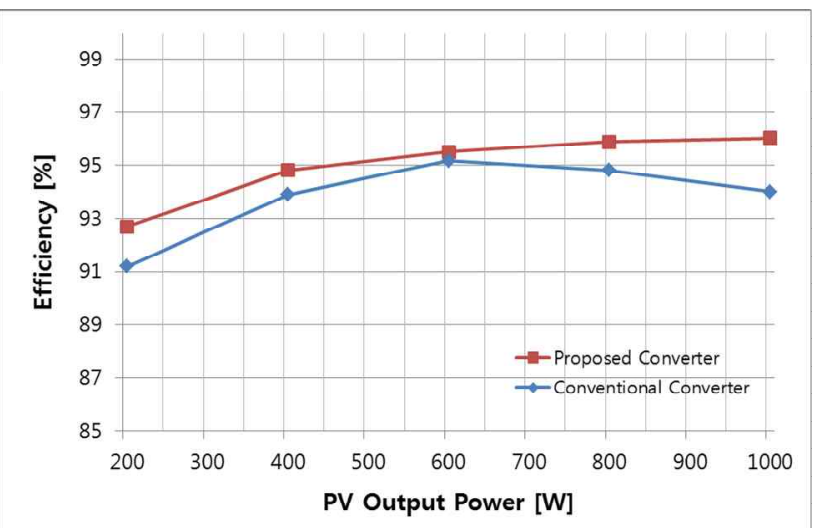

Fig. 15. The efficiency of the proposed and conventional topologies in boost mode.

Fig. 13 shows the waveforms of gate signals and the main switch current and voltage. Before the main gate signal is turned on, the voltage of main switch becomes zero.

Consequently, when the main switch gate signal is turned off, the voltage of the main switch is zero instantaneously.

Fig. 14 shows the ZCS operation of the auxiliary switch. Compared with simulation results, auxiliary switch current shows almost same results, and the experimental waveform clearly shows that the main and auxiliary switches are operated under ZVS and ZCS condition respectively.

The efficiency comparison between the proposed converter and the conventional hard switching converter with load variation is shown in Fig. 15. The measurement was progressed under 0.5 duty condition. The measured maximum efficiency in boost mode is $96.03[\%]$. Moreover, the measured maximum efficiency in buck mode is $96.15[\%]$ as well.

\section{CONCLUSIONS}

In this paper, a novel bidirectional DC-DC converter using ZVS has been proposed that uses auxiliary switches and auxiliary resonant circuit. The main switches and the auxiliary switches are operated under zero voltage and zero current condition by employing the resonant circuit. Since the soft switching technique is employed, the efficiency of the bidirectional converter is increased, and the switching loss is decreased as well. Therefore, the maximum efficiency of the proposed converter shows over 96[\%] under full load condition. In order to verify the validity of the proposed bidirectional DC-DC converter, mode analysis, design consideration, simulation results and experimental results are proven. Particularly, the experiment is progressed by building a $1[\mathrm{~kW}], 30[\mathrm{kHz}]$ soft-switching bidirectional converter prototype regulated at $200\left[\mathrm{~V}_{\mathrm{dc}}\right]$ input voltage and $400\left[\mathrm{~V}_{\mathrm{dc}}\right]$ output voltage.

\section{ACKNOWLEDGMENT}

This work was supported by the National Research Foundation of Korea(NRF) grant funded by the Korea government(MEST) (No.2012-0005371)

\section{REFERENCES}

[1] F. Z. Peng, Li Hui, G. J. Su, and J. S. Lawler, "A new ZVS bidirectional DC-DC converter for fuel cell and battery application," IEEE Trans. Power Electron., Vol. 19, No.1, pp. 64-65, Jan. 2004.

[2] M D. Jain and P. Jain, "A bidirectional DC-DC converter topology for low power application," IEEE Trans. Power Electronics, Vol. 15, No. 4, pp. 595-606, Jul. 2000.

[3] M. Pahlevaninezhan, P. Das, J. Drobnik, P. K. Jain, A. Bakhshai, "A New Control Approach Based on The Differential Flatness Theory for an AC/DC Converter Used in Electric Vehicles," IEEE Trans. Power Electron., Vol. 27, No.4, pp. 2085-2103, Apr. 2012.

[4] M. Jain, M. Daniele, and P. K. Jain, "A bidirectional DC-DC converter topology for low power application," IEEE Trans. Power Electron., Vol. 15, No.4, pp. 595-606, Jul. 2000.

[5] H. Li, F. Z. Peng, and J. S. Lawler, "A natural ZVS medium-power bidirectional DC-DC converter with minimum number of devices," IEEE Trans. Ind. Appl., Vol. 39, No. 2, pp. 525-535, Mar. 2003.

[6] S. Inoue and H. Akagi, "A bidirectional isolated DC-DC converter as a core circuit of the next-generation medium-voltage power conversion system," IEEE Trans. Power Electron., Vol. 22, No. 2, pp. 535-542, Mar. 2007.

[7] L. Schuch, and C. Rech, H. L. Hey, H. A. Grundling, and H. Pinheiro, "Analysis and design of a new high-efficiency bidirectional integrated ZVT PWM converter for dc-bus and battery-bank interface," IEEE Trans. Ind. Appl., Vol. 42, No. 5, pp. 1321-1332, Sep. 2006.

[8] P. Das, B. Laan, S. A. Mousavi, and G. Moschopoulos, "A nonisolated bidirectional ZVS-PWM active clamped DC-DC converter," IEEE Trans. Ind. Appl., Vol. 24, No. 2, pp. 553-558, Feb. 2009.

[9] G. Hua, C.-S. Leu, Y. Jiang, and F. C. Y. Lee, "Novel zero-voltage transition PWM converters," IEEE Trans. Power Electron., Vol. 9, No.2, pp. 213-219, Mar. 1994.

[10] B.R. Lin and J. J. Chen, "Analysis and implementation of a soft switching converter with high-voltage conversion ratio," IET Power Electronics, Vol. 1, No. 3, pp. 386-394, Sep. 2008.

[11] H. Bodur and A. F. Bakan, "A new ZVT-PWM DC-DC converter," IEEE Trans. Power Electron., Vol. 17, No. 1, 
pp. 40-47 Jan. 2002

[12] J. H. Kim, D. Y. Jung, S. H. Park, C. Y. Won, Y. C. Jung, and S. W. Lee, "High efficiency soft-switching boost converter using a single switch," Journal of Power Electronics, Vol. 9, No. 6, pp. 929-939, Nov. 2009.

[13] S. R. Park, S. H. Park, C. Y. Won, and Y. C. Jung, "Low loss soft switching boost converter," in Proc. $13^{\text {th }}$ Power Electronics on Motion Control Conference in 2008, pp. 181-186, Sep. 2008.

[14] N. Jain, P. K. Jain, and G. Joos, “A zero voltage transition boost converter employing a soft switching auxiliary circuit with reduced conduction losses," IEEE Trans. Power Electron., Vol. 19, No. 1, pp. 130-139, Jan. 2004.

[15] P. Das, B. Laan, S. A. Mousavi, and G. Moschopoulos, "A nonisolated bidirectional ZVS-PWM active clamped DC-DC converter," IEEE Trans. Power Electron., Vol. 24 No. 2, pp. 553-558, Feb. 2009.

[16] H. Mao, O. A. Rahman, and I. Batarseh, "Zero-voltage-switching DC-DC converters with synchronous rectifiers," IEEE Trans. Power Electron., Vol. 23, No. 1, pp. 369-378, Jan. 2008

[17] G. Hua, and F. C. Lee, "Soft switching techniques in PWM converter," IEEE Trans. Ind. Electron., Vol. 42, pp. 595-603, Dec. 1995

[18] H. Farzanehfard, E. Adib, A. Jusoh, and Z. Salam, "A fully soft switched two quadrant bidirectional soft switching converter for ultra capacitor interface circuits," Journal of Power Electronics, Vol. 11, No. 1, pp. 1-9, Jan. 2011.

[19] I. D. Kim, J. Y. Kim, E. C. Nho, and H. G. Kim, "Analysis and design of a soft-switched PWM sepic DC-DC converter," Journal of Power Electronics, Vol. 10, No. 5, pp. 461-467, Sep. 2010.

[20] D. Y. Lee, M. K. Lee, K. S. Hyun, and I. Choy, "New zero-current-transition PWM DC/DC converters without current stress," IEEE Trans. Power Electron., Vol. 18, No. 1, pp. 95-104, Jan. 2003.

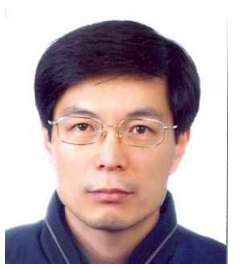

Ju-Kyoung Eom was born in Korea in 1971 He received his B.S. and M.S. in Electrical Engineering from Korea University, Seoul, Korea, in 1988 and 1990 respectively. From 1990 to 2002, he was with LSIS R\&D Center, Anyang, Korea, where he worked on the development of VVVF. From 2003 to 2004, he was a senior engineer in Corecess Co., Korea. Since 2005, he has been a R\&D Director in Intech FA Co., His current research interests include power electronics application and control of energy conversion in various industrial fields.

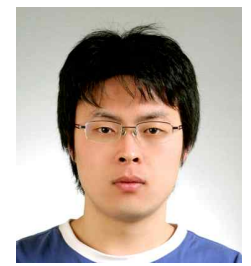

Jun-Gu Kim was born in Korea, in 1981. $\mathrm{He}$ received the M.S. degree from the Graduate College of Photovoltaic System Engineering, Sungkyunkwan University, Suwon, Korea, in 2009, where he is currently working toward the Ph.D. degree. His research interests include converters, inverters, bidirectional converter, battery charging/discharging and its control for renewable energy applications.

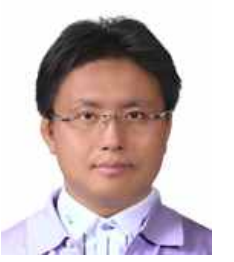

Jae-Hyung Kim was born in Korea in 1975. $\mathrm{He}$ received the B.S. and M.S. degrees in electrical engineering from the University of Dong-Eui, Busan, Korea, in 1995 and 2002, respectively. $\mathrm{He}$ is currently working toward the Ph.D. degree in the College of Information and Communication Engineering, Sungkyunkwan University, Suwon, Korea. $\mathrm{He}$ is currently a senior research engineer in the SAMSUNG TECHWIN R\&D center.

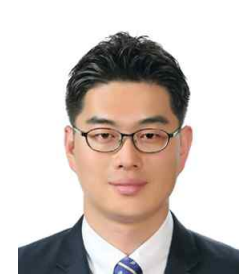

Soon-Tack Oh was born in 1981 in Korea. He received the B.S. degree in Faculty of Electronic Engineering from Namseoul univertisy, and M.S. degree in College of Information and Communication Engineering from Sungkyunkwan University, Suwon, Korea, in 2010 and 2012, respectively. He is currently an assistant engineer in the SAMSUNG Electro-Mechanics.

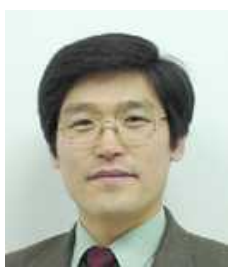

Yong-Chae Jung was born in Korea in 1965. He received the B.S. degree from Hanyang University, Seoul, Korea, in 1989, and the M.S. and Ph.D. degrees in Electrical Engineering from the Korea Advanced Institute of Science and Technology (KAIST), Daejeon, Korea, in 1991 and 1995, respectively. $\mathrm{He}$ is currently an associate professor in the department of Electronic Engineering at Namseoul University. His research interests include design and control of power converters, soft switching power converters, resonant power circuits, photovoltaic system, power factor corrections, SMPS, induction heating circuit and EMI suppression. He is a member of the Korea Institute of Power Electronics (KIPE), and Korea Institute of Electrical Engineering (KIEE).

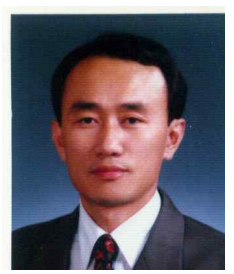

Chung-Yuen Won was born in Korea in 1955. He received the B.S. degrees in Electrical Engineering from Sungkyunkwan University, Suwon, Korea, in 1978, and the M.S. and Ph.D. degrees in Electrical Engineering from Seoul National University, Seoul, Korea, in 1980 and 1987, respectively. From 1990 to 1991, he was with the Department of Electrical Engineering, University of Tennessee, Knoxville, as a Visiting Professor. Since 1988, he has been with a member of the faculty of Sungkyunkwan University, where he is a Professor in the College of Information and Communication Engineering; also he is the director of Samsung Energy Power Research Center. He was the President of the Korean Institute of Power Electronics in 2010. Since 2011, he has been a director of the Korean Federation of Science and Technology Societies. His current research interests include the power electronic of electric machines, electric/hybrid vehicle drives, power converters for renewable energy systems. He is a senior member of the Institute of Electrical and Electronics Engineers (IEEE). 